\title{
Transperitoneal Laparoskopik Nefrektomi
}

\author{
Lütfi Tunç, Esat Ak
}

Gazi Üniversitesi, Tıp Fakültesi, Üroloji Anabilim Dalı, Ankara

\section{Giriş}

T aparoskopik nefrektomi ilk olarak 1991 yılında transpeـritoneal olarak gerçekleştirilmiştir (1). O tarihten beri, birçok merkez yaptığı çalışmalarda açık cerrahiyle karşılaştırıldığında laparoskopik yaklaşımın avantajlarını bildirmişlerdir (2-4). Ancak, bugüne kadar yapılmış çoğu çalışmada, transperitonal nefrektomi için kullanılan yöntem standart basit nefrektomi için kulanılan yöntem ile paralelik göstermektedir. Az sayıdaki çalışmada transperitoneal laparoskopik nefrektomi için alternatif teknikler araştırılmıştır $(5,6-8)$. Bu makalenin amac1, transperitoneal laparoskopik nefrektomi tekniğimizi bazı önemli püf noktaları ile birlikte aktarmaktır. Kullandığımız yöntemin, açık ve standart transperitoneal laparoskopik nefrektomi tekniklerden en önemli farkı, diseksiyona böbrek üst polünden başlanması ve renal pediküle olan yaklaşımdır.

\section{Hasta Hazırlığı}

Transuretral Foley kateter ve nasogastrik tüp yerleştirilir ve hasta 70 derece lateral dekübitis pozisyonuna getirilir.

\section{Portların Yerleştirilmesi}

Sağ veya sol nefrektomide karın üzerinde bir üçgen oluşturacak şekilde 3 adet port yerleştirilir (Şekil 1). Önce, yerleştirilecek en sefalik port bölgesi işaretlenir. Bu bölge

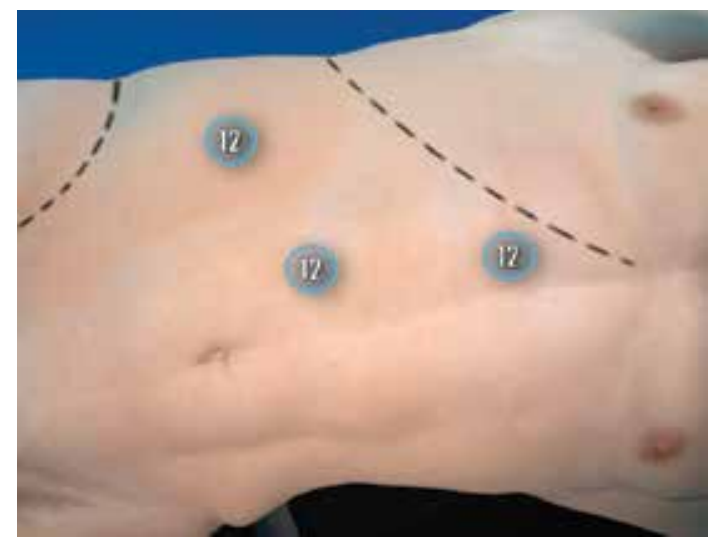

Şekil 1: Sağnefrektomide port yerleşimi. Numaralı işaretlerin herbiri $12 \mathrm{~mm}$ olan trokar girişlerini göstermektedir rektusabdominis kasının $2 \mathrm{~cm}$ laterali ve kosta kenarının 1 cm aşağısıdır. Bu bölgeye komşu, 3-5 cm aşağ $\mathrm{cm}$ medialinde başka bir bölge işaretlenir. Bu bölge kamera portunun bölgesi olacaktır. 3. bölge umblicusun $8-10 \mathrm{~cm}$ lateralindedir. Bu bölgeler işaretlendikten sonra, kamera port bölgesine $1 \mathrm{~cm}$ 'lik bir cilt insizyonu yapılır. Fasyaya kadar makas ile künt diseksiyon yapılır. Makasın ucuyla fasyada 1-2 mm'lik bir insizyon yapılır. Veress iğnesi buradan girilir ve peritonun abdominal organlardan uzaklaşması için cilt kaldırılırken iğne kibarca karın içine ilerletilir. Ardından $14 \mathrm{mmHg}$ 'lık bir pneumoperitoneum oluşturulur. Daha sonra Veress iğnesi çıkarılır çıkarılmaz künt uçlu $12 \mathrm{~mm}$ trokar onun yerine yerleştirilir. Kamera girişini takiben diğer iki 12 $\mathrm{mm}$ künt trokar optik vizyon altında yerleştirilir.

\section{Sağ Nefrektomide Cerrahi Teknik}

\section{Karaciğer altından periton insizyonu}

Böbrek üst polünü göstermek için, trianguler ligamentin 10-15 cm medialinden başlayan ve karaciğer altından ilerleyerek triangular ligamente kadar devam eden peritoneal insizyonu yapılır (Şekil 2).

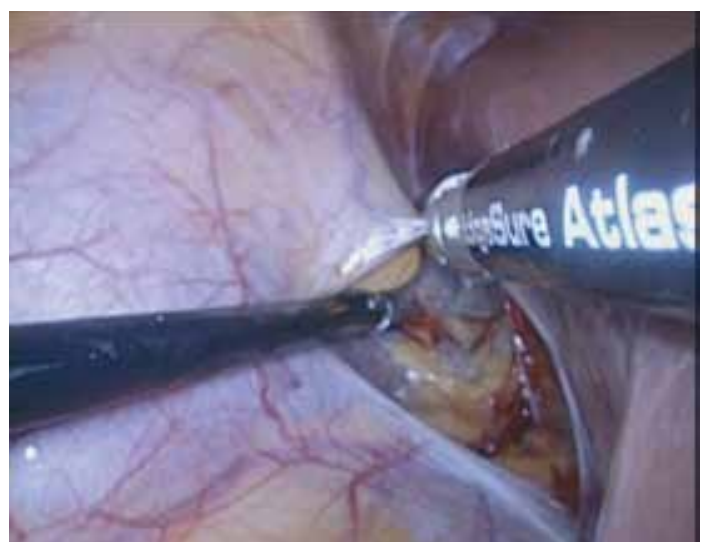

Şekil 2: Karaciğer altından peritoninsizyonu

\section{Kolon mobilizasyonu}

Periton kesisi vena kavaya paralel olarak, inferiora doğru uzatılır. Bu adım sırasında, kolon minimal mediale çekilir. Sağ taraf nefrektomisinde, sadece böbreğin alt polünü saran kolonu devirmek daha kolay olmaktadır. Duodeneum dikkatlice mediale mobilize edilir. Böbreğin alt polüne ulaşıldığında, psoas kasını ortaya çıkarmak için böbrek kaldırılır. 


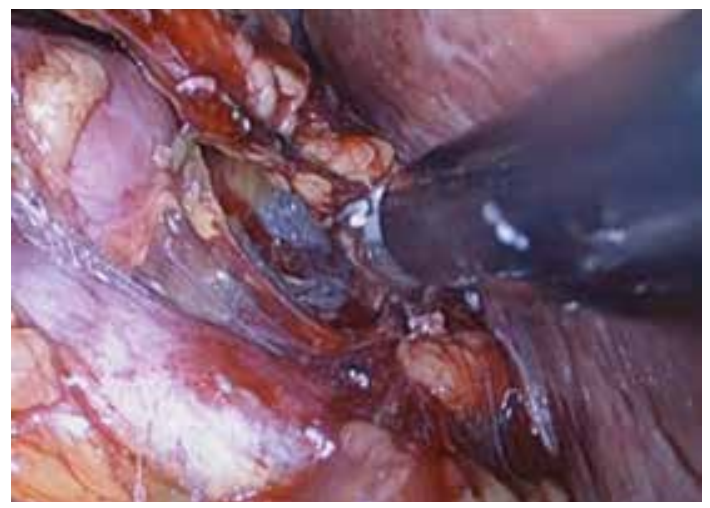

Şekil 3: Morrison boşluğuna giriş (karaciğeri böbrekten ayıran hepatorenal girinti veya subhepatik girinti)

Renal pedikül seviyesinde, renal pedikül önündeki Gerota fasyası ve bağ dokusu mekanik ve bipolar enerji ile üst pole kadar vena kava boyunca disseke edilir. Renal ven ve vena kava açıkça görülebildiği zaman, renal ven ve vena kava bileşkesinin üst tarafı disseke edilir. Bu adım sırasında, künt uçlu aletle (bipolar, aspiratör veya disektörü) künt diseksiyon uygulanır. Bu bileşkede renal ven üstünden ve vena kava lateralinden geçip karaciğer, böbrek üst pol posterioru ve vena kavanın lateral yüzü tarafından sinırlanan anatomik bir boşluk olan Morrison boşluğuna (hepatorenal girinti veya subhepatik girinti) (Şekil 3) girilir. Bu anatomik boşluktan genellikle ürolojik cerrahi kitaplarında hiç bahsedilmemektedir. Pnömoperiton varlığında, bu alanın ortaya konulması daha kolay olabilmektedir.

Böbreküstü bezi yerinde bırakılacaksa adrenal bez ve böbrek arasındaki doku bipolar ile disseke edilir iken, sağ el aletleri (atravmatik grasper, aspiratör vb.) böbrek üstü bezini laterale ve süperiora çeker. Bu şekilde, böbreküstü bezi tamamen böbreğin üst polünden ayrılır. Adrenalektomi yapılacaksa, vena kavaya açılan adrenal ven ortaya çıkarılır. Morrison alanında sol eldeki enstrüman böbreği ve böbreküstü bezini laterale çekerken sağ eldeki enstrüman (bipolar enerji kaynağ mühürlenir ve kesilir. Bu diseksiyon sırasında, bölgedeki diğer böbreküstü bezi damarları disseke edilir. Bu diseksiyonun sonucu olarak, böbrek üst polü ve adrenal bez çevre yapılardan tamamen serbestlenir.

\section{Böbrek alt pol diseksiyonu}

Alt kutup psoas kası, üreter ve böbrek pedikül inferiorunu ortaya çıkarmak için çevre dokulardan disseke edilir.

\section{Renal arter ve venin diseksiyonu ve ligasyonu}

Renal arter ve ven bipolar alet ve aspiratör (Şekil 4) ile disseke ve izole edilir. Daha sonra, renal arter üzerine, genellikle üç adet Hem-o-Lok klip (iki adet hastada kalan kısma ve bir adet de böbrek ile çıkarılacak bölüme) yerleştirilir. Daha sonra renal ven anatomiye ve venin çapına bağlı olarak Hem-o-Lok klip (iki adet hastada kalan kismina, bir adet de böbrek ile çıkarılacak kısmma) veya vasküler stapler ile ligate edilir. Diğer bir seçenek ise renal arter ve venin vasküler stapler ile bütün olarak ligate edilmesidir. Vasküler stapler ile bütün halinde ligasyon, pedikül diseksiyonu sırasında çok sayıda arter veya ven görülürse tercih edilir. Operasyonun kısa sürmesi gereken, yaşlı, kardiyopulmoner hastalıkları

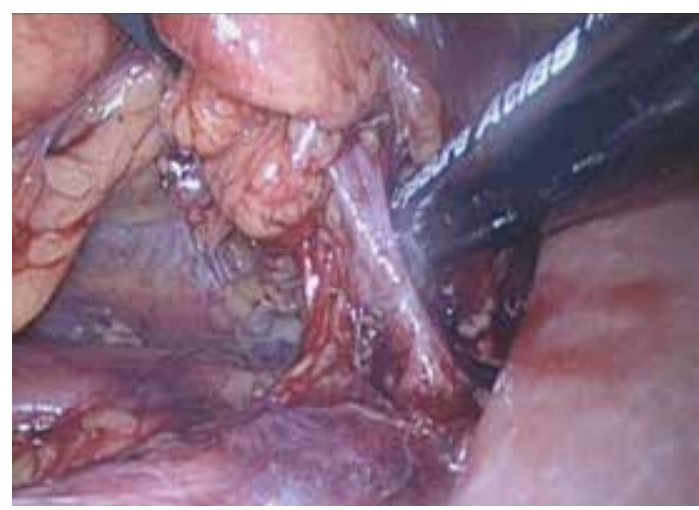

Şekil 4: Renal pedikül diseksiyonu (renal arter ve ven)

olan hastalarda da; pnömoperitoneum süresini kısaltmak için bütün olarak ligasyon tercih edilebilir. Bizim serimizde bütün halinde ligasyon yaptığımız hastaların hiçbirinde arteriovenöz fistül saptanmamıştır (9).

\section{Üreterin ayrılması ve böbreğin tamamen serbestleştirilmesi}

Son olarak, üreter oraya çıtıktan sonra iki Hem-o-Lok klip üretere mümkün olduğu kadar distale yerleştirilir, üreter klipslerin arasından kesilir. Böbrek tüm çevre dokulardan serbestleştirildikten sonra, bir organ torbası içerisine yerleştirilir ve çıkarılır.

\section{Sol nefrektomide cerrahi teknik}

Hasta hazırlanması ve port yerleştirilmesi yukarıda sağ nefrektomi için tarif edilenlerle aynıdır. Portlar yerleştirildikten sonra kolonun medialize edilmesine olanak sağlayan dalak seviyesinden iliak damarlara uzanan Toldt hattı boyunca bir insizyon yapılır. Daha sonra böbrek üst polünü ortaya çıkarmak için splenokolik ve splenorenal ligamanlar diseke edilir. Bu diseksiyon için künt uçlu bipolar enstrumanlar (Ligasure gibi) tercih edilir.

Adrenal bez yerinde birakılacaksa adrenal ven ve renal ven bileşkesi künt diseksiyonlarla ortaya konur. Adrenal ven, renal ven ve böbreğin sinırladığ 1 boşluktan psoas kasına kadar diseksiyon derinleştirilir (Şekil 5). Sol eldeki enstruman (atravmatik grasper, aspirator vs.) ile adrenal bez laterale ve superiora retrakte edilirken adrenal ve böbrek arasındaki doku bipolar ile diseke edilir.

$\mathrm{Bu}$ yolla adrenal bez böbrek üst polünden tamamen

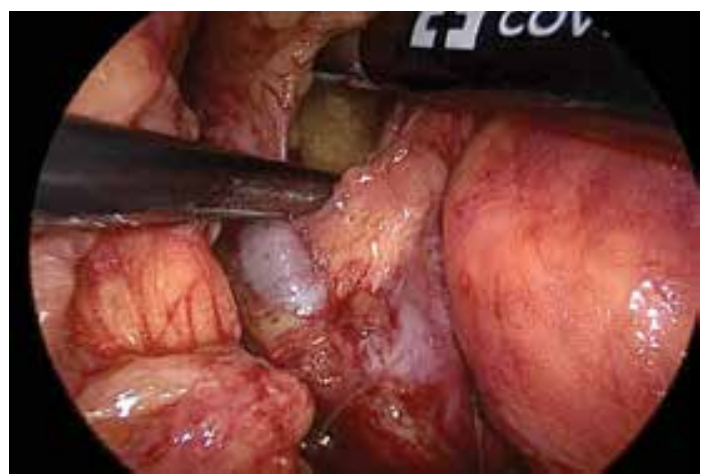

Şekil 5: Adrenal ven, renalven ve böbrek ile sınırlı boşluk 
ayrılır. Adrenalektomi yapılacaksa adrenal ven ve renal ven bileşkesi bulunduktan sonra psoasa doğru uzanan diseksiyon adenal ven, renal ven ve vena kavanın sınırladığı alandan başlatılır. Sonra bipolar koterle, adrenal bez medialindeki ve superiorundaki doku ve damarlar disseke edilir.

Sol böbreğin alt pol diseksiyonu, renal arter ve venin ayrılması ve ligasyonu, üreterin ayrılması ve ligasyonu ve nefrektominin tamamlanması sağ nefrektomi için yukarıda tarif edilen ile aynidir.

\section{Sonuç}

Laparoskopik nefrektomi böbrek üst polünden başlayan diseksiyon yoluyla hızlı ve güvenli bir şekilde yapılabilir. Bu tekniğin önemli bir avantajı da pneumoperitoneum süresinin daha kısa olmasıdır. Pnömoperitoneum süresi arttığında kardiyopulmoner problemleri olan hastalarda komplikasyon riski artmaktadır. Dolayısıyla kısa operasyon zamanı bu hastalarda riski azaltmaktadır. Transperitoneal laparoskopik sağ nefrektomi, ilgili alandaki yapıların anatomisi nedeniyle zor bir işlem olarak kabul edilir, özellikle bu yöntemle sağ nefrektomi Morrison alanının diseksiyonu ve ortaya konulması ile daha kolay yapılabilmektedir.

\section{Kaynaklar}

1. Clayman RV, Kavoussi LR, Soper NJ, et al. Laparoscopicnephrectomy. N Engl J Med. 1991;324:13701.

2. Hsiao W, Pattaras JG. Not so "simple" laparoscopic nephrectomy: outcomes and complications of a 7-year experience. J Endourol. 2008; 22: 2285-2290.
3. Burgess NA, Koo BC, Calvert RC, et al. Randomized trial of laparoscopic vs. open nephrectomy. J Endourol. 2007; 21: 610-613.

4. Pareek G, Hedican SP, Gee JR, et al. Meta-analysis of the complications of laparoscopic renal surgery: comparison of procedures and techniques. J Urol. 2006; 175: 12081213.

5. Graham SD, Keane TE, Glenn JF. Glenn's Urologic Surgery, p. 820-823. Lippincott Williams \& Wilkins, 2010.

6. Porpiglia F, Terrone C, Cracco C, et al. Direct access to the renal artery at the level of Treitz ligament during left radical laparoscopic transperitoneal nephrectomy. Eur Urol 2005;48: 291-295.

7. Porpiglia F, Renard J, Billia M, et al. Left laparoscopic radical nephrectomy with direct access to the renal artery: technical advantages. Eur Urol. 2006; 49: 1004-1010.

8. Tunc $\mathrm{L}$ et al. Direct upper kidney pole access and early ligation of renal pedicle significantly facilitates transperitoneal laparoscopic nephrectomy procedures: Tunc technique. Surg Laparosc Endosc Percutan Tech. 2011 Dec; 21(6): 453-7.

9. Atkin MS et al. The risk of arteriovenous fistula formation after en bloc stapling of the renal hilum during transperitoneal laparoscopic nephrectomies. Surg Laparosc Endosc Percutan Tech. 2014; 24: 80-4.

Yazışma Adresi:

Lütfi Tunç,

Gazi Üniversitesi, Tıp Fakültesi,

Üroloji Anabilim Dal, Ankara

Tel: +90 5325460994

e-mail:lutfitunc@gmail.com 